\title{
Association between Arsenic and Generalized Anxiety Disorder: A Cross-Sectional Study
}

\author{
Lei Zhang"\#, Minzhi Cao ${ }^{2 \#}$, Linnan Guo ${ }^{1}$, Li Wang ${ }^{3}$, Min Zhang 3 , Jiajia Qian ${ }^{3}$, Scottie Bussell ${ }^{4}$, Na Wang ${ }^{\text {*, Suhua Wang }}$ Su $^{*}$ \\ ${ }^{1}$ School of Public Health, Guilin Medical University, Guilin530021, Guangxi, China \\ ${ }^{2}$ Bayannaoer Center for Disease Control and Prevention, Bayannaoer 015000, Inner Mongolia China \\ ${ }^{3}$ School of Public Health, Baotou Medical College, Baotou014040, Inner Mongolia, China \\ ${ }^{4}$ Department of Health and Human Services, Parker Indian Hospital, Parker, Arizona, USA. \\ \# These authors contributed equally to this work.
}

* Corresponding Authors: Na Wang, School of Public Health, Guilin Medical University, Guilin 530021, Guangxi,China. Suhua Wang, School of Public Health, Baotou Medical College, Baotou014040, Inner Mongolia, China.

Received date: April 12, 2021; Accepted date: April 19, 2021; Published date: April 27, 2021

Citation: Na Wang, Lei Zhang, Minzhi Cao, Suhua Wang, Li Wang et all (2021) Association Between Arsenic And Generalized Anxiety Disorder: A Cross-Sectional Study. J. Women Health Care and Issues, 4(4); DOI:10.31579/2642-9756/054

Copyright: () $2021 \mathrm{Na}$ Wang, This is an open access article distributed under the Creative Commons Attribution License, which permits unrestricted use, distribution, and reproduction in any medium, provided the original work is properly cited.

\begin{abstract}
Aim: In some regions of Bayannaoer arsenic concentration in well drinking water is higher than the international standard of $10 \mu \mathrm{g} / \mathrm{L}$. The purpose of this study is to evaluate the impact of exposures to arsenic in drinking water on generalized anxiety disorder (GAD)

Materials and Methods: A survey was conducted in 2016 among villagers in Hangjinhou County, Bayannaoer City, Inner Mongolia. A questionnaire was used to inquire about GAD, arsenic related neurological symptoms. Arsenic concentration in the water was measured and arsenicosis prevalence was assessed. Multinomial logistic regression and ordinal logistic regression were performed to evaluate the association of abnormal arsenic levels on increased GAD symptoms.

Results: 446 participants were enrolled. Subjects with exposure to water arsenic levels $>10 \mu \mathrm{g} / \mathrm{L}$ were significantly more likely to have mild GAD than controls (adjusted odds ratio $[\mathrm{AOR}]=2.3,95 \%$ confidence interval [CI], 1.1-4.8). Participants who were diagnosed with arsenicosis were more likely to report mild anxiety than minimal anxiety compared to those who did not $(\mathrm{AOR}=2.3,95 \% \mathrm{CI}, 1.3-4.1)$. Survey respondents with palpitations, forgetfulness, headaches, dizziness, decreased taste, decreased hearing, loss of touch, abnormal warm and cold sensation, blurred vision, numbness and tingling were more likely to report mild, moderate and severe anxiety.
\end{abstract}

Conclusions: Arsenic exposure was associated with a higher risk of GAD. Screening for arsenic exposure should be incorporated into the evaluation of GAD, in areas where arsenic in drinking water is known to be abnormal.

Keywords: arsenic; generalized anxiety disorder

\section{Introduction}

Anxiety disorders are common psychiatric disorders among various people [1-4]. Generalized anxiety disorder (GAD) is the most common anxiety disorder [5]. People with GAD diagnostic often show excessive and persistent inexplicable tensions and fears with a lack of specific objects and specific content [6].

GAD has serious economic and social burdens in China. In the urban China, the prevalence of GAD was 5.3\% [7]. Individuals with GAD are more likely to have suicidal ideation and attempt suicide than persons with other anxiety disorders $[8,9]$.

Arsenic exists in a high level in groundwater across Inner Mongolia Province in northern China, including Bayannao'er, a prefecture-level city on the Hetao Plain. Bayannao'er is a major endemic area with high concentration of arsenic in groundwater (543 villages with concentration $>50 \mu \mathrm{g} / \mathrm{L}$ ) [10]. People are exposed through drinking water [10]. Arsenic related adverse health effects in this region are well known [10-13]. In 1995, 81\% of all arsenicosis cases, mainly skin hyperkeratosis, depigmentation, hyperpigmentation and skin cancer, in Inner Mongolia were from Bayannaoer and there was a dose-response between the prevalence of arsenicism and concentration of arsenic in drinking water [10].

As arsenic can cross the blood-brain barrier and accumulate in nerve tissues, a study have reported that drinking water arsenic exposure causes a variety of neuropsychiatric symptoms, including hearing loss, taste loss, blurred vision, limb numbness and tingling[14]. Studies have found that arsenic exposure is associated with anxiety disorders [15-18]. Moreover, 
arsenic is neurotoxic $[19,20]$. Higher levels of arsenic in drinking water are associated with a higher rate of suicide, which may be correlated with arsenic related anxiety [21]. A study reported that $4.61 \%$ of arsenicosis patients had mixed anxiety and depressive disorders and $0.26 \%$ had GAD [15].

Since 2001, both central and local governments have invested in drivingwater improvement programs to reduce fluorine and arsenic levels in drinking water in Inner Mongolia. Local residents were supplied with water that reduced arsenic levels by centralized water wells. Despite efforts by local governments in Bayannaoer, at the end of 2011, arsenic concentration in well drinking water was higher than the international standard of $10 \mu \mathrm{g} / \mathrm{L}$ in some regions. For example, local surveillance data showed water arsenic level $>80 \mu \mathrm{g} / \mathrm{L}$ for four consecutive years in Defeng village, Hangjinhou county. Public health officials and mental health professions are concerned that this level of arsenic in drinking water may be contributing to excess anxiety disorder prevalence.

We conducted a cross-sectional study in Hangjinhou County to investigate the prevalence of GAD among local residents and assess the association between arsenic, such as arsenic in drinking water, arsenicosis and arsenic related neurological symptoms, and GAD.

\section{Materials and Methods}

\section{Study Design}

In December 2016, a cross-sectional survey was conducted among residents in Hangjinhou County. According to whether arsenic in drinking water $>10 \mathrm{ug} / \mathrm{L}$, all the villages were divided into two layers, then, villages were randomly selected from these two layers. Four villages (Defeng, Gaofeng, Chunguang and Zhongnanqu in Hangjinghou County were selected. Defeng, Gaofeng and Chunguang were covered by two improvement wells with water arsenic concentration $>10 \mu \mathrm{g} / \mathrm{L}$. Zhongnanqu was supplied by one improvement well with water arsenic concentration $<10 \mu \mathrm{g} / \mathrm{L}$ as a control. All adult residents in these four villages were invited for eligibility screening. Those who were 18 years or older, lived in study villages for at least 10 years, and provided consent were eligible and enrolled in the study. This study was approved by the institutional review board of Baotou Medical College.

\section{Data Collection}

Personal interviews were conducted by trained interviewers to collect demographic data including age, gender, ethnicity, education, marital status, occupation, family income in the past 12 months, duration of living in study sites, out-migration in the past 12 months, medical history, arsenic related neurological symptoms (e.g. palpitations, forgetfulness, headaches and dizziness, decreased taste, decreased hearing loss, loss of touch, abnormal warm and cold sensation, blurred vision, numbness and tingling) and GAD symptoms in the last 2 weeks.

GAD was measured using a 7-item scale Generalized Anxiety Disorder
(GAD-7) (Cronbach's alpha $=0.89$ in our study). The GAD-7 scale has seven items on the symptoms of GAD over the last 2 weeks. A sum score is calculated by adding the answers of all items on a four-point Likert scale (0-3) ranging from 0 to 21 . The scores of $0-4,5-9,10-14$ and 15 or more are categorized as minimal, mild, moderate and severe anxiety, respectively [22].

Arsenicosis was diagnosed by physicians familiar with patients with this disorder. Diagnostic criteria for endemic arsenic poisoning (WS/T 2112005) included: living in an endemic arsenic area, having a history of excessive arsenic exposure, and having keratosis of the metacarpophalangeal skin [23].

Since the water improvement project was completed in 2011 in all of the 4 study villages, residents around the wells shared the same drinking water source. Participants in our study lived near three wells thus water samples from three improvement wells were collected and tested for arsenic concentration. Water samples were collected with sterile polyethylene bottles and arsenic levels were measured using a spectrophotometer with a detection limit of $10 \mu \mathrm{g} / \mathrm{L}$ (T6, Puxi Co. Beijing, China).

\section{Statistical Analysis}

Epidata 3.1 software was used for data entry and management. SAS version 9.2 (SAS Institute, Cary, NC) was used for statistical analysis. The primary dependent variable was GAD, which was classified into four categories as described above. The main predictor of GAD were arsenic concentration in drinking water, arsenicosis and as well as arsenic related neurological symptoms. Simple descriptive statistics for the main outcome and predictors were calculated. Multinomial logistic regressions and ordinal logistic regression were used. ORs were calculated with age group and gender adjusted models and fully adjusted models that included age group, gender, ethnic, education, marital status, occupation, family income in the last 12 months, duration of living in study villages, ever out-migration in the past 12 months, and medical history.

\section{Results}

Of 459 residents from 4 villages, 446 (97\%) were enrolled in the study. Age ranged from 18 to 86 years old. The majority of participants were farmers $(94.2 \%), 18-60(65.7 \%)$ years old, female (59.0\%), Han ethnic $(98.4 \%)$, married $(91.3 \%)$, and had an elementary school education or less $(55.2 \%)$. Most participants had lived in the study villages for 20 years or more (94.8\%), had a family income of more than 15,000 RMB in the last 12 months $(60.5 \%)$, did not leave the villages in the past 12 months (88.4\%), and had no comorbidities (56.0\%).

Of all participants, $71.8 \%(320 / 446)$ had minimal anxiety, $18.6 \%(83 / 446)$ had mild anxiety, $4.9 \%(22 / 446)$ had moderate anxiety, and $4.7 \%(21 / 446)$ had severe anxiety. Compared to minimal anxiety, mild, moderate and severe anxiety were significantly $(p<0.05)$ more likely in females and those with comorbidities. (Table 1).

\begin{tabular}{|c|c|c|c|c|c|c|}
\hline \multirow[b]{2}{*}{ variable } & \multirow[b]{2}{*}{$\mathbf{N}(\%)$} & \multicolumn{4}{|c|}{ Generalized anxiety disorder severity* } & \multirow[b]{2}{*}{$\boldsymbol{P}$} \\
\hline & & $\begin{array}{l}\text { Minimal } \\
(0-4)\end{array}$ & $\begin{array}{l}\text { Mild } \\
(5-9)\end{array}$ & $\begin{array}{l}\text { Moderate } \\
(10-14)\end{array}$ & $\begin{array}{l}\text { Severe } \\
(\geq 15)\end{array}$ & \\
\hline \multicolumn{7}{|l|}{ Village } \\
\hline Defeng & $225(50.4)$ & $162(72.0)$ & $44(19.6)$ & $12(5.3)$ & $7(3.1)$ & \\
\hline Chunguang & $84(18.8)$ & $54(64.3)$ & $17(20.2)$ & $5(6.0)$ & $8(9.5)$ & \\
\hline Gaofeng & $42(9.4)$ & $26(61.9)$ & $12(28.6)$ & $2(4.8)$ & $2(4.8)$ & \\
\hline Zhongnanqu & $95(21.3)$ & $78(82.1)$ & $10(10.5)$ & $3(3.2)$ & $4(4.2)$ & 0.10 \\
\hline \multicolumn{7}{|c|}{ Age group in years } \\
\hline $18-60$ & $293(65.7)$ & $211(72.0)$ & $54(18.4)$ & $12(4.1)$ & $16(5.5)$ & \\
\hline $61-86$ & $153(34.3)$ & $109(71.2)$ & $29(19.0)$ & $10(6.5)$ & $5(3.3)$ & 0.52 \\
\hline Gender & & & & & & \\
\hline
\end{tabular}




\begin{tabular}{|l|l|l|l|l|l|l|}
\hline Male & $183(41.0)$ & $144(78.7)$ & $29(15.9)$ & $4(2.2)$ & $6(3.3)$ & \\
\hline Female & $263(59.0)$ & $176(66.9)$ & $54(20.5)$ & $18(6.8)$ & $15(5.7)$ & 0.02 \\
\hline Ethnicity & $439(98.4)$ & $315(71.8)$ & $82(18.7)$ & $21(4.8)$ & $21(4.8)$ & 0.64 \\
\hline Education & & & & & \\
\hline Middle school or above & $200(44.8)$ & $152(76.0)$ & $33(16.5)$ & $5(2.5)$ & $10(5.0)$ & \\
\hline Primary school or below & $246(55.2)$ & $168(68.3)$ & $50(20.3)$ & $17(6.9)$ & $11(4.5)$ & 0.10 \\
\hline Marital status & $407(91.3)$ & $297(73.0)$ & $74(18.2)$ & $17(4.2)$ & $19(4.7)$ & 0.08 \\
\hline Occupation & $420(94.2)$ & $300(71.4)$ & $80(19.1)$ & $19(4.5)$ & $21(5.0)$ & 0.20 \\
\hline Family income in the last 12 months (RMB, Yuan) & & & & & \\
\hline$\geq 15,000$ & $270(60.5)$ & $191(70.7)$ & $50(18.5)$ & $16(5.9)$ & $13(4.8)$ & \\
\hline$<15,000$ & $176(39.5)$ & $129(73.3)$ & $33(18.8)$ & $6(3.4)$ & $8(4.6)$ & 0.69 \\
\hline Living locally & $423(94.8)$ & $303(71.6)$ & $79(18.7)$ & $21(5.0)$ & $20(4.7)$ & 0.10 \\
\hline Out-migration in the past 12 months & $52(11.7)$ & $30(57.7)$ & $16(30.8)$ & $4(7.7)$ & $2(3.9)$ & 0.06 \\
\hline Current heart disease & $194(44.0)$ & $119(61.3)$ & $48(24.7)$ & $13(6.7)$ & $14(7.2)$ & $<0.01$ \\
\hline
\end{tabular}

*measured by GAD-7; RMB: Renmenbi, approximately US $\$ 0.15$.

Table 1. Characteristics of participants, Bayannaoer City in Northern China, $2016(N=446)$

Among 446 participants, 50.4\% (225) drank water with arsenic contaminant level at $80 \mu \mathrm{g} / \mathrm{L}, 28.2 \%$ (126) drank water with arsenic level at $20 \mu \mathrm{g} / \mathrm{L}$, and a total of $78.7 \%$ (351) drank well water with arsenic contaminant level $>10 \mu \mathrm{g} / \mathrm{L}$, and $21.3 \%$ (95) drank water with $<10 \mu \mathrm{g} / \mathrm{L}$ arsenic.

$24.4 \%$ (109) were diagnosed with arsenicosis. Some of them had arsenic related neurological symptoms, such as palpitations (35.2\%), forgetfulness $(61.2 \%)$, headaches and dizziness $(50.0 \%)$, decreased taste $(10.3 \%)$, decreased hearing $\operatorname{loss}(27.1 \%)$, loss of touch $(2.7 \%)$, abnormal warm and cold sensation(12.6\%), blurred vision(50.7\%), numbness and tingling $(30.3 \%)$.

Compared to minimal anxiety, mild anxiety was significantly $(p<0.05)$ more likely in those with arsenicosis. Compared to minimal anxiety, mild, moderate and severe anxiety was more common in palpitations, forgetfulness, headaches and dizziness, decreased taste, decreased hearing loss, loss of touch, abnormal warm and cold sensation, blurred vision, numbness and tingling $(p<0.05)$. (Table 2)

\begin{tabular}{|l|l|l|l|l|l|l|}
\hline \multirow{2}{*}{ Variable } & \multirow{2}{*}{$\mathbf{N}(\boldsymbol{\%})$} & \multicolumn{6}{l}{ Generalized anxiety disorder severity* } \\
\cline { 4 - 8 } & & $\begin{array}{l}\text { Minimal } \\
\mathbf{( 0 - 4 )}\end{array}$ & $\begin{array}{l}\text { Mild } \\
\mathbf{( 5 - 9})\end{array}$ & $\begin{array}{l}\text { Moderate } \\
(\mathbf{1 0 - 1 4})\end{array}$ & $\begin{array}{l}\text { Severe } \\
(\mathbf{1 5 - 2 1})\end{array}$ & $\boldsymbol{P}$ \\
\hline Arsenic in drinking water & & & & & 0.08 \\
\hline$<10 \mu \mathrm{g} / \mathrm{L}$ & $95(21.3)$ & $78(82.1)$ & $10(10.5)$ & $3(3.2)$ & $4(4.2)$ & \\
\hline$>10 \mu \mathrm{g} / \mathrm{L}$ & $351(78.7)$ & $242(69.0)$ & $73(20.8)$ & $19(5.4)$ & $17(4.8)$ & \\
\hline Arsenicosis & $109(24.4)$ & $71(65.1)$ & $30(27.5)$ & $2(1.8)$ & $6(5.5)$ & 0.01 \\
\hline Palpitations & $157(35.2)$ & $89(56.7)$ & $38(24.2)$ & $17(10.8)$ & $13(8.3)$ & $<0.01$ \\
\hline Forgetfulness & $273(61.2)$ & $179(65.6)$ & $57(20.9)$ & $20(7.3)$ & $17(6.2)$ & $<0.01$ \\
\hline Headaches and dizziness & $223(50.0)$ & $138(61.9)$ & $54(24.2)$ & $15(6.7)$ & $16(7.2)$ & $<0.01$ \\
\hline Decreased taste & $46(10.3)$ & $23(50.0)$ & $10(21.7)$ & $5(10.9)$ & $8(17.4)$ & $<0.01$ \\
\hline Decreased hearing loss & $121(27.1)$ & $68(56.2)$ & $30(24.8)$ & $14(11.6)$ & $9(7.4)$ & $<0.01$ \\
\hline Loss of touch & $12(2.7)$ & $3(25.0)$ & $3(25.0)$ & $3(25.0)$ & $3(25.0)$ & $<0.01$ \\
\hline Abnormal warm and cold sensation & $56(12.6)$ & $21(37.5)$ & $16(28.6)$ & $11(19.6)$ & $8(14.3)$ & $<0.01$ \\
\hline Blurred vision & $226(50.7)$ & $148(65.5)$ & $45(19.9)$ & $15(6.6)$ & $18(8.0)$ & $<0.01$ \\
\hline Numbness and tingling & $135(30.3)$ & $81(60.0)$ & $33(24.4)$ & $12(8.9)$ & $9(6.7)$ & $<0.01$ \\
\hline
\end{tabular}

*measured by GAD-7.

Table 2. Generalized anxiety disorder prevalence by arsenic exposure and arsenic related neurological symptoms among 446 participants (n/\%)

Participants who drinking water with arsenic concentration over $10 \mu \mathrm{g} / \mathrm{L}$ were more likely to report mild anxiety than minimal anxiety compared to those with arsenic within $10 \mu \mathrm{g} / \mathrm{L}$ according to the multinomial logistic regressions, in the age group and gender adjusted models $(\mathrm{AOR}=2.4,95 \%$ CI, 1.2-4.8) and fully adjusted models (AOR=2.3, 95\% CI, 1.1-4.8). Participants who were diagnosed with arsenicosis were more likely to report mild anxiety than minimal anxiety compared to those did not in the age group and gender adjusted models (AOR=2.4, 95\% CI, 1.4-4.1) and fully adjusted models ( $\mathrm{AOR}=2.3$, 95\% CI, 1.3-4.1). Palpitations $(\mathrm{AOR}=3.0,95 \% \mathrm{CI}, 2.0-4.6),(\mathrm{AOR}=2.7,95 \% \mathrm{CI}, 1.6-4.0)$, forgetfulness $(\mathrm{AOR}=2.3,95 \% \mathrm{CI}, 1.4-3.6),(\mathrm{AOR}=2.0,95 \% \mathrm{CI}, 1.2-3.2)$, headaches and dizziness $(\mathrm{AOR}=2.5,95 \% \mathrm{CI}, 1.6-3.9),(\mathrm{AOR}=2.2,95 \% \mathrm{CI}, 1.4-3.5)$, decreased taste $(\mathrm{AOR}=3.5,95 \% \mathrm{CI}, 1.9-6.3),(\mathrm{AOR}=3.2,95 \% \mathrm{CI}, 1.7-$ $6.0)$, decreased hearing loss $(\mathrm{AOR}=2.9,95 \% \mathrm{CI}, 1.9-4.6),(\mathrm{AOR}=2.8$, 95\% CI, 1.7-4.5), loss of touch (AOR=11.0, 95\% CI, 3.8-31.9), $(\mathrm{AOR}=7.9,95 \% \mathrm{CI}, 2.5-25.0)$, abnormal warm and cold sensation ( $\mathrm{AOR}=5.8,95 \% \mathrm{CI}, 3.3-9.9),(\mathrm{AOR}=5.6,95 \% \mathrm{CI}, 3.1-9.9)$, blurred vision $(\mathrm{AOR}=1.9,95 \% \mathrm{CI}, 1.3-2.9),(\mathrm{AOR}=2.1,95 \% \mathrm{CI}, 1.3-3.2)$, numbness and tingling $(\mathrm{AOR}=2.1,95 \% \mathrm{CI}, 1.4-3.2),(\mathrm{AOR}=1.7,95 \% \mathrm{CI}, 1.1-2.7)$ were more likely to report mild, moderate and severe anxiety in the age group and gender adjusted models and fully adjusted models of multiple ordinal logistic regression. (Table 3) 


\begin{tabular}{|c|c|c|c|}
\hline \multirow[b]{2}{*}{ Variable } & \multicolumn{3}{|c|}{ Level of anxiety as measured by GAD-7, AOR (95\% CI $)$} \\
\hline & $\begin{array}{l}\text { Mild } \\
(5-9)\end{array}$ & $\begin{array}{l}\text { Moderate } \\
(10-14)\end{array}$ & $\begin{array}{l}\text { Severe } \\
(15-21)\end{array}$ \\
\hline \multirow[t]{2}{*}{ Arsenic in drinking water $>10 \mu \mathrm{g} / \mathrm{L}$} & $2.4(1.2,4.8)^{* a}$ & $2.0(0.6,7.2)^{\mathrm{a}}$ & $1.4(0.4,4.2)^{\mathrm{a}}$ \\
\hline & $2.3(1.1,4.8)^{* b}$ & $1.8(0.5,6.8)^{b}$ & $1.2(0.4,3.9)^{\mathrm{b}}$ \\
\hline \multirow[t]{2}{*}{ Arsenicosis } & $2.4(1.4-4.1)^{* a}$ & $0.5(0.1-2.0)^{\mathrm{a}}$ & $1.6(0.6-4.3)^{\mathrm{a}}$ \\
\hline & $2.3(1.3-4.1)^{* b}$ & $0.4(0.1-1.9)^{b}$ & $1.5(0.5-4.4)^{b}$ \\
\hline \multicolumn{4}{|l|}{ Arsenic related neurological symptoms } \\
\hline \multirow[t]{2}{*}{ Palpitations } & $3.0(2.0-4.6)^{* a}$ & & \\
\hline & $2.7(1.6-4.0) * b$ & & \\
\hline \multirow[t]{2}{*}{ Forgetfulness } & $2.3(1.4-3.6)^{* a}$ & & \\
\hline & $2.0(1.2-3.2)^{* b}$ & & \\
\hline \multirow[t]{2}{*}{ Headaches and dizziness } & $2.5(1.6-3.9)^{* a}$ & & \\
\hline & $2.2(1.4-3.5)^{* b}$ & & \\
\hline \multirow[t]{2}{*}{ Decreased taste } & $3.5(1.9-6.3)^{* a}$ & & \\
\hline & $3.2(1.7-6.0)^{* b}$ & & \\
\hline \multirow[t]{2}{*}{ Decreased hearing loss } & $2.9(1.9-4.6) * a$ & & \\
\hline & $2.8(1.7-4.5)^{* \mathrm{~b}}$ & & \\
\hline \multirow[t]{2}{*}{ Loss of touch } & $11.0(3.8-31.9)^{* a}$ & & \\
\hline & $7.9(2.5-25.0)^{*} \mathrm{~kb}$ & & \\
\hline \multirow[t]{2}{*}{ Abnormal warm and cold sensation } & $5.8(3.3-9.9)^{* a}$ & & \\
\hline & $5.6(3.1-9.9)^{* b}$ & & \\
\hline \multirow[t]{2}{*}{ Blurred vision } & $1.9(1.3-2.9)^{* a}$ & & \\
\hline & $2.1(1.3-3.2)^{* \mathrm{~b}}$ & & \\
\hline \multirow[t]{2}{*}{ Numbness and tingling } & $2.1(1.4-3.2) * a$ & & \\
\hline & $1.7(1.1-2.7)^{* b}$ & & \\
\hline
\end{tabular}

Table 3 Association between arsenic and $G A D(N=446)$

${ }^{*}$ The variable was significant at 0.05 level; a adjusted for age group and gender; ${ }^{b}$ Adjusted for age group, gender, ethnic, education, marital status, occupation, family income in the last 12 months, duration of living in study villages, ever out-migration in the past 12 months, and medical history.

\section{Discussion}

In our study, the rate of moderate and severe GAD was $10.2 \%$ and $7.4 \%$ among a sample of people living in an arsenic endemic zone and control regions. Both were higher than urban Chinese of 5.3\% [7] , the higher rate of this rural area may be contributed by financial pressure and health care and especially arsenic exposure.

Our study showed that there was a statistically significant association between mild GAD with arsenicosis and exposure to a moderate level of arsenic in drinking water ( $\operatorname{arsenic}>10 \mu \mathrm{g} / \mathrm{L}$ ). A study from India revealed that a higher prevalence of anxiety was reported in arsenic endemic zones (arsenic in groundwater, $10-50 \mu \mathrm{g} / \mathrm{L}$ ) than in control regions $(\leq 10 \mu \mathrm{g} / \mathrm{L})$ [17]. A study reported that $4.61 \%$ of arsenicosis patients had mixed anxiety and depressive disorders and $0.26 \%$ had GAD [15], but the study did not have non-arsenicosis controls.

To our knowledge, there are few studies assessing the relationship between GAD and moderate level of arsenic centration in drinking water and arsenicosis. After the water-improvement campaign was completed in 2011 across all arsenic endemic regions in Bayannaoer, residents had access to water with lower arsenic levels. So the level of arsenic in the improvement wells' water that they were using could not reflect the level of arsenic intake. In consideration of that, we measured arsenicosis to reflect arsenic exposure. Arsenicosis is caused by long term (6 months plus) ingestion of arsenic above a safe dose, characterized by skin lesions and possible involvement of internal organs [24]. Arsenicosis reflects a cumulative exposure of arsenic. Our study also measured arsenic related neurological symptoms to assess the relationship between arsenic and GAD comprehensively.

There are several limitations to our study. First, we could not prove the relationship between exposures to arsenic and GAD using this cross- sectional design. Second, since the late 1970s, deep artesian wells were popular, which were often contaminated by arsenic in Bayanaoer [25], some people may be exposed to arsenic for nearly 50 years. We were unable to estimate the total amount of arsenic that study participants had ingested because the water quality was improved and the arsenic in drinking water was reduced. Future studies could measure the arsenic level of the deep artesian wells and drinking year history. Third, due to the measure of self-reporting of $\mathrm{GAD}$, prevalence might be underreported in the questionnaire interview. However, we selected villages randomly from two layers with water arsenic $>10 \mu \mathrm{g} / \mathrm{L}$ or $<10 \mu \mathrm{g} / \mathrm{L}$, and all participant outcomes were measured in the same way, so possible reporting bias in different groups would have been proportionate. Fourth, participants were recruited by radio broadcasting, so people with severe diseases might not respond.

\section{Conclusion}

Mild GAD was statistically significantly associated with arsenicosis and exposure to moderate level of arsenic in drinking water. People with arsenic exposure, especially in endemic areas; should be asked routinely about GAD screening.

\section{Conflict Of Interest Statement:}

The authors declare no conflict of interest.

\section{Acknowledgements}

This work was funded in part by National Natural Science Foundation of China, Grant number 81760616 and number 81660532 . 


\section{References:}

1. Shao S, Wang J, Huang K, Wang S, Liu H, Wan S, et al. Prenatal pregnancy-related anxiety predicts boys' ADHD symptoms via placental C-reactive protein. Psychoneuroendocrinology 2020, 120:104797.

2. Creswell C, Nauta MH, Hudson JL, March S, Reardon T, Arendt K, et al. Research Review: Recommendations for reporting on treatment trials for child and adolescent anxiety disorders - an international consensus statement. J Child Psychol Psychiatry 2020.

3. Chisholm D, Sweeny K, Sheehan P, Rasmussen B, Smit F, Cuijpers $P$, et al. Scaling-up treatment of depression and anxiety: a global return on investment analysis. Lancet Psychiatry 2016, 3:415-424.

4. Bosman RC, Ten Have M, de Graaf R, Muntingh AD, van Balkom AJ, Batelaan NM. Prevalence and course of subthreshold anxiety disorder in the general population: A three-year follow-up study. J Affect Disord 2019, 247:105-113.

5. Hou R, Garner M, Holmes C, Osmond C, Teeling J, Lau L, et al. Peripheral inflammatory cytokines and immune balance in Generalised Anxiety Disorder: Case-controlled study. Brain Behav Immun 2017, 62:212-218.

6. He H, Xiang Y, Gao F, Bai L, Fan Y, Lyu J, et al. Comparative efficacy and acceptability of first-line drugs for the acute treatment of generalized anxiety disorder in adults: A network meta-analysis. J Psychiatr Res 2019, 118:21-30.

7. Yu W, Singh SS, Calhoun S, Zhang H, Zhao X, Yang F. Generalized anxiety disorder in urban China: Prevalence, awareness, and disease burden. J Affect Disord 2018, 234:89-96.

8. Nock MK, Hwang I, Sampson NA, Kessler RC. Mental disorders, comorbidity and suicidal behavior: results from the National Comorbidity Survey Replication. Mol Psychiatry 2010, 15:868-876.

9. Raichle ME. The brain's dark energy. Sci Am 2010, 302:44-49.

10. Ma HZ, Xia YJ, Wu KG, Sun TZ, Mumford JL. Human exposure to arsenic and health effects in Bayingnormen, Inner Mongolia. Arsenic Exposure and Health Effects (Chappell WR, Abernathy CO, Calderon R, eds). Amsterdam: Elsevier 1999:127-131.

11. Mumford JL, Wu K, Xia Y, Kwok R, Yang Z, Foster J, et al. Chronic arsenic exposure and cardiac repolarization abnormalities with QT interval prolongation in a population-based study. Environ Health Perspect 2007, 115:690-694.

12. Wade TJ, Xia Y, Wu K, Li Y, Ning Z, Le XC, et al. Increased mortality associated with well-water arsenic exposure in Inner Mongolia, China. Int J Environ Res Public Health 2009, 6:1107-1123.

13. Xia Y, Wade TJ, Wu K, Li Y, Ning Z, Le XC, et al. Well water arsenic exposure, arsenic induced skin-lesions and self-reported morbidity in Inner Mongolia. Int J Environ Res Public Health 2009, 6:1010-1025.
14. Guo JX, Hu L, Yand PZ, Tanabe K, Miyatalre M, Chen Y. Chronic arsenic poisoning in drinking water in Inner Mongolia and its associated health effects. J Environ Sci Health A Tox Hazard Subst Environ Eng 2007, 42:1853-1858.

15. Sen D, Sarathi Biswas P. Arsenicosis: Is it a Protective or Predisposing Factor for Mental Illness? Iran J Psychiatry 2012, 7:180183.

16. Dang WM, Ma WJ, Wang S, Shi C, Su LP, Guan HY, et al. [Investigation on mental health of residents living in a mineral area in Hubei province]. Zhonghua Lao Dong Wei Sheng Zhi Ye Bing Za Zhi 2008, 26:457-460.

17. Mukherjee B, Bindhani B, Saha H, Sinha D, Ray MR. Platelet hyperactivity, neurobehavioral symptoms and depression among Indian women chronically exposed to low level of arsenic. Neurotoxicology 2014, 45:159-167.

18. Fujino Y, Guo X, Liu J, You L, Miyatake M, Yoshimura T. Mental health burden amongst inhabitants of an arsenic-affected area in Inner Mongolia, China. Soc Sci Med 2004, 59:1969-1973.

19. Itoh T, Zhang YF, Murai S, Saito H, Nagahama H, Miyate H, et al. Theeffect of arsenic trioxide on brain monoamine metabolism and locomotor activity of mice. Toxicol Lett 1990, 54:345-353.

20. Zhang W, Cui X, Gao Y, Sun L, Wang J, Yang Y, et al. Role of pigment epithelium-derived factor (PEDF) on arsenic-induced neuronal apoptosis. Chemosphere 2019, 215:925-931.

21. Rihmer Z, Hal M, Kapitany B, Gonda X, Vargha M, Dome P. Preliminary investigation of the possible association between arsenic levels in drinking water and suicide mortality. J Affect Disord 2015, 182:23-25

22. Spitzer RL, Kroenke K Fau - Williams JBW, Williams Jb Fau - Lowe $\mathrm{B}$, Lowe B. A brief measure for assessing generalized anxiety disorder: the GAD-7. 2006.

23. Wang W, Wang Q, Zou Z, Zheng F, Zhang A. Human arsenic exposure and lung function impairment in coal-burning areas in Guizhou, China. Ecotoxicol Environ Saf 2020, 190:110174.

24. Sachan S, Pathania S, Mahdi AA, Suvirya S, Singhai A. Case Report of Cutaneous Squamous Cell Carcinoma at the Wrist Joint and the Public Health Crisis of Arsenicosis. J Health Pollut 2021, 11:210314.

25. Ma HZ, Xia YJ, Wu KG, Sun TZ, Mumford JL. Human Exposure to Arsenic and Health Effects in Bayingnormen, Inner Mongolia A2 Chappell, Willard R. In: Arsenic Exposure and Health Effects III. Edited by Abernathy CO, Calderon RL. Oxford: Elsevier Science Ltd; 1999. pp. 127-131.
This work is licensed under Creative Commons Attribution 4.0 License

To Submit Your Article Click Here: Submit Manuscript

DOI: $10.31579 / 2642-9756 / 054$
Ready to submit your research? Choose Auctores and benefit from:

*ast, convenient online submission
*igorous peer review by experienced research in your field
*apid publication on acceptance
* unthors retain copyrights
* immedian DOI for all articles
immediate, unrestricted online access

At Auctores, research is always in progress.

Learn more https://www.auctoresonline.org/journals/women-health-careand-issues 